\title{
CORRIGENDUM
}

\section{Postglacial vegetation dynamics at high elevation from Fairy Lake in the northern Greater Yellowstone Ecosystem, Montana, USA - Corrigendum}

James V. Benes, Virginia Iglesias and Cathy Whitlock

DOI: https://doi.org/10.1017/qua.2019.9, Published by Cambridge University Press, 05 April 2019.

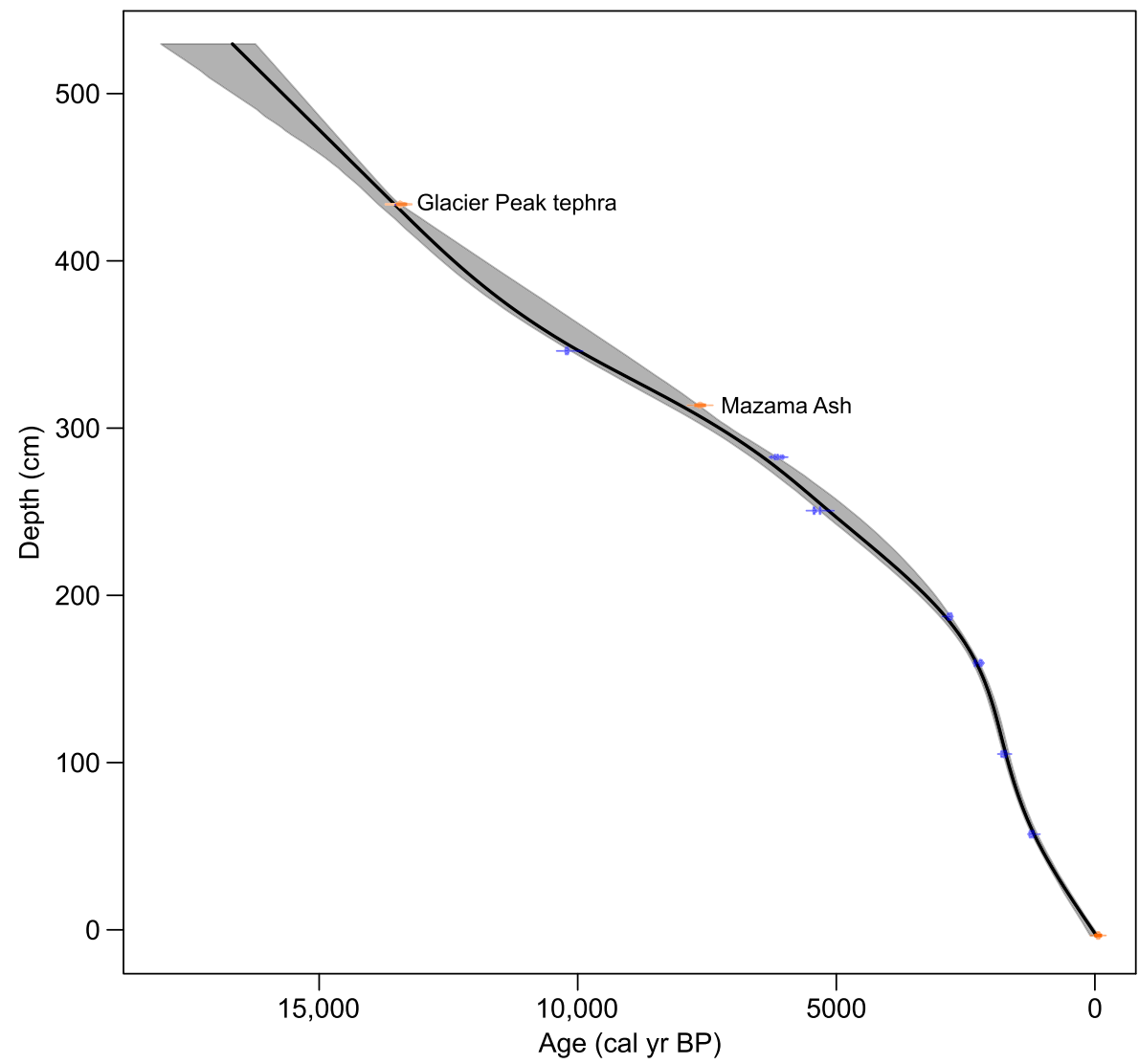

Figure 2. Age-depth model for Fairy Lake. 95\% confidence intervals are shown in gray. The distributions of the calibrated ages employed in the development of the chronology are shown in purple and orange (samples submitted for 14C analysis and published ages of tephra deposition, respectively). (For interpretation of the references to color in this figure legend, the reader is referred to the web version of this article.)

Cite this article: Benes, J. V., Iglesias , V., Whitlock, C. 2019. Postglacial vegetation dynamics at high elevation from Fairy Lake in the northern Greater Yellowstone Ecosystem, Montana, USA Corrigendum. Quaternary Research 92, 606-607. https://doi.org/ 10.1017/qua.2019.22
In the original publication of this article (Benes et al.), the captions for Figures 2 and 3 were inadvertently switched. The figure captions should read as follows:

The authors apologize for this error. 


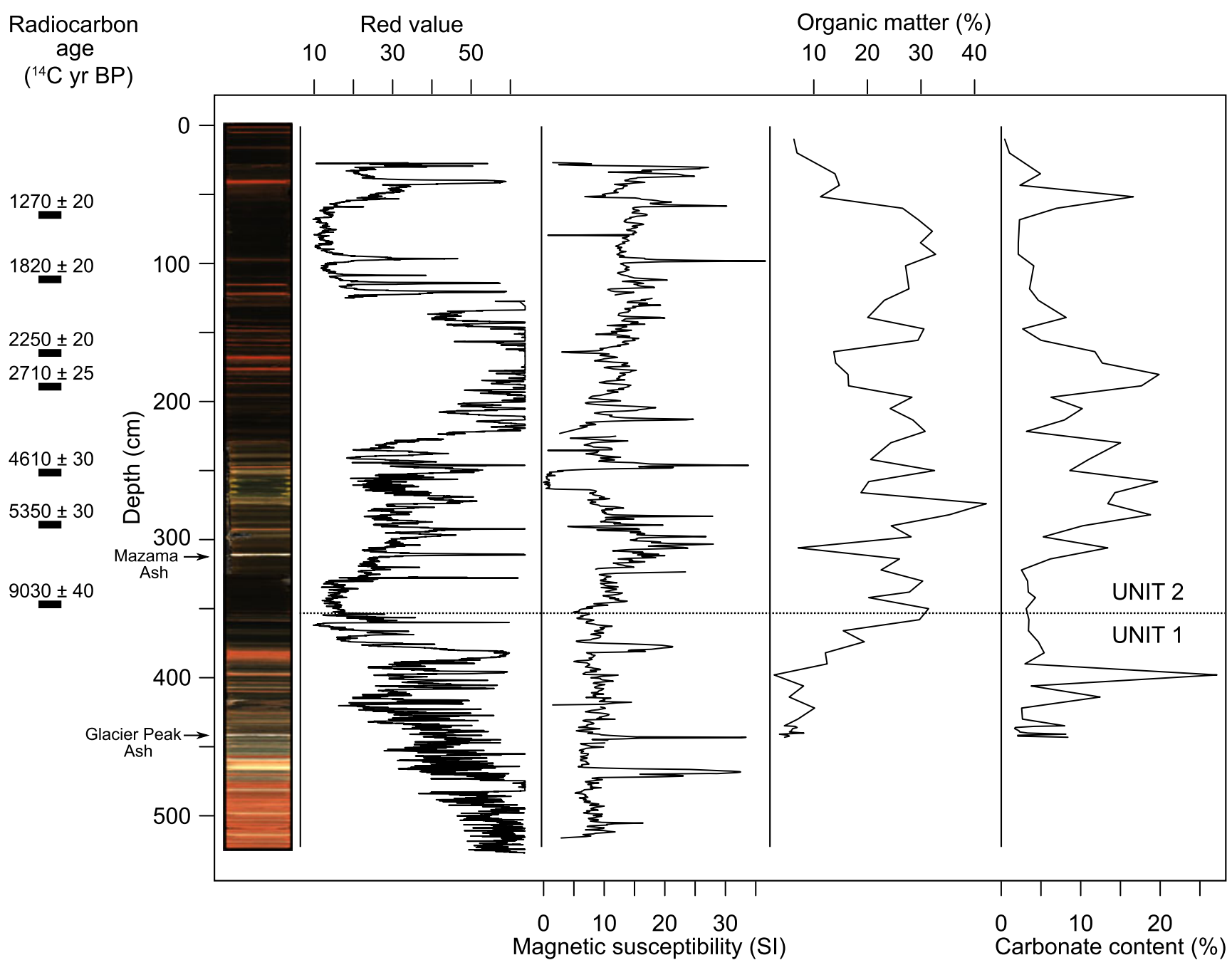

Figure 3. Lithology, red-value intensity, magnetic susceptibility (SI), carbonate content (\%), and organic matter (\%) from Fairy Lake. Lithological units 1 and 2 are shown. The black rectangles represent 14C dates. (For interpretation of the references to color in this figure legend, the reader is referred to the web version of this article.)

\section{Reference}

Benes, J., Iglesias, V., \& Whitlock, C. Postglacial vegetation dynamics at high elevation from Fairy Lake in the northern Greater Yellowstone Ecosystem, Montana, USA. Quaternary Research, 1-16. doi:10.1017/qua.2019.9. Published online 05 April 2019. 